\title{
MODELING CONCURRENT OPERATIONAL INTERRUPTIONS IN CONSTRUCTION ACTIVITIES WITH SIMPLIFIED DISCRETE EVENT SIMULATION APPROACH (SDESA)
}

\author{
Ming Lu \\ Wah-Ho Chan \\ Department of Civil and Structural Engineering \\ Hong Kong Polytechnic University \\ Hung Hom, Hong Kong S.A.R. CHINA
}

\begin{abstract}
Numerous previous applications have demonstrated the high potential of discrete simulation methodologies in designing and analyzing construction systems. Still, construction simulation applications largely remain software exercises at the academic level because of the time and effort as required in constructing a valid simulation model that matches the real processes and operations. This paper introduces an enhanced version of the Simplified Discrete Event Simulation Approach (SDESA) by incorporating a concurrent interruptions model, which is intended to make construction simulations more realistic without compromising the simplicity of the original SDESA. Particular emphasis is placed on how to model the effects of operational interruptions upon the system performance by applying SDESA. The well-established CYCLONE method acts as a cross-validation tool to check the results given by SDESA. And the validity and simplicity of SDESA modeling are illustrated with a simple earthmoving operation simulation and a real hoist and barrow concreting operation simulation.
\end{abstract}

\section{INTRODUCTION}

The complex interactions among resource units on the construction job site and various constraints in the harsh construction environment hamper a systemic, detailed, and costeffective endeavor for construction process planning and control. Computer-based discrete simulation techniques have been proven as an effective tool to study complex systems particularly for those that preclude conventional mathematical or analytical treatment (Law and Kelton 1982). Hence simulation provides the potential means for designing and analyzing construction systems and improving effectiveness and efficiency on construction operations.

Although numerous previous applications have demonstrated the high potential of adopting simulation as a construction management tool, most simulation applications largely remain a software exercise at the academic and experimental level (McCahill and Bernold 1993). The main obstacles to widespread use of simulation by construction practitioners are identified to be the complexity of the simulation methodologies and time requirements involved in constructing a model which is capable of representing the actual technology, resource, and site conditions (Paulson 1995, Shi and AbouRizk 1997). How to enhance the model's validity while reducing the modeling effort has aroused intense interest of researchers and spawned a host of innovative simulation methods and tools. Some developments (such as GPSS) are powerful enough to embed operation details into their models, but usually code or scripts must be written for each specific project, leading to a long learning period and an inefficient model building/updating process. On the other hand, many researchers attempted to shorten the user learning curve and simplify the modeling procedure by reducing the number of basic modeling elements or visualizing input/output. One significant body of research in this area has centered on the CYCLONE methodology (short for CYClic Operation NEtwork) - developed for construction operations simulation by Halpin at the University of Illinois in the early 1970s based on the activity cycle diagram (ACD) concept for discrete-event simulation (Halpin 1977). However, such non-programmable simulation approaches as CYCLONE were considered to be impractical or inadequate for modeling some real construction operations, as the resources of a certain type are assumed to have the same attributes and perform without difference in the same task while the response to the changes in site condition and resource availability encountered on the job site are usually overlooked (McCahill \& Bernold 1993). Since the inception of CYCLONE, its merits and features have been extended by many by enriching and advancing its modeling functionalities (Martinez and Ioannou 1999).

This paper introduces an enhanced version of the Simplified Discrete Event Simulation Approach (SDESA) by incorporating a concurrent interruptions model, which is intended to make construction simulations more realistic while the simplicity of the original SDESA is not compromised. Particular emphasis is placed on how to model the effects of 
operational disruptions due to random resource breakdowns and regular activity interruptions upon the system performance by applying SDESA. The CYCLONE method acts as a cross-validation tool to check the results given by SDESA.

\section{LITERATURE REVIEWS ON SITE INTERFERENCE}

The method productivity delay model (MPDM) - developed by Adrian in 1970s as an enhancement to the work sampling technique- classified construction delays into five categories, namely, environmental delay, labor delay, equipment delay, management delay, and material delay, and quantified the effects of delays of each type upon the method productivity loss (Halpin and Riggs 1992). Parker and Oglesby (1972) categorized unavailable human resources on construction sites and identified the most significant category as organized daily breaks for coffee, lunch, etc., which delay all the work tasks where humans are directly involved. In a study of non-steady construction process, Bernold (1989) highlighted the effect of resource breakdowns upon the productivity rate of the concreting process, showing that even a small portion of resource breakdown can lead to a significant drop on the overall productivity (Bernold 1989). Activity progress and resource availability depend on various factors on the jobsite, and the regular activity interruptions or random resource breakdowns are proved to be one significant factor which can give direct impact to the system performance and project duration (Damrianant and Wakefield 2000). The inevitable occasional/routine stoppages of each piece of working equipment - due to operator breaks, minor maintenance, refueling, lubrication, tire or track repair etc. are generally programmed in the process simulation model to stop work progress on a random basis, with the total percentage of downtime over a large number of cycles completed being equal to the historical stoppage percentage for that particular type of equipment (McCahill and Bernold 1993).

In general, activity interruptions in the construction field occur due to (1) the unexpected events such as random equipment failure, unpredictable weather factors, unforeseen underground conditions etc.; and (2) the prescheduled events such as periodic equipment maintenance, crew coffee breaks or lunch hours etc. Nonetheless, the effects of activity interruptions on the system performance are not as straightforward to analyze with discrete event simulation methods. For example, in a customer-server queuing system, while the server is engaged in serving a customer, the event of "server breakdown start" will disrupt the ongoing process by disengaging the server and customer. Because the total service time is pre-determined, the remaining service time is calculated and recorded. The customer is immediately placed back on the head of the queue and stay in the waiting state. The server is in the idle state and remains unavailable till the event of "server breakdown end" is triggered. Then the customer is pulled out of the queue and the server resumes the service with the customer for the remainder of the service time. Modeling such a simple activity interruption entails processing a series of events by an event-based simulation executive, i.e. (1) schedule the "activity interruption start" event (place the customer entity back in the queue, calculate and store the remaining service time, change the server's state from available to unavailable), (2) cancel the prescheduled "End of Service" event in the event list, (3) schedule the "activity interruption end" event (change the server state back to 'available' and pull the customer from the queue), and (4) re-schedule the "End of Service" event after the remainder of service time.

The executive program of SDESA controls the simulation operations by manipulating two dynamic queues, namely, the flow entity queue and the resource entity queue ( $\mathrm{Lu}$ 2003a). A flow entity, passing through a sequence of activities in a process, is an essential element with common time attributes to initialize activity and acts as a counter to control the execution of an activity. SDESA distinguishes disposable resource entities from reusable resource entities, and uses disposable resource entities to represent those intermediate products or command units that are generated during the simulation process and can be used once only. The computer system of SDESA has recently been redeveloped in VC 6.0 with enhancements particularly to its capability of modeling resource breakdowns and activity interruptions (Lu 2003b). In SDESA, a combination of the probability and downtime define a delay caused by random resource breakdown (Figure 3a). The probability is a decimal between 0 and 1 , with 0 standing for no chance and 1 for certainty for the breakdown to occur. The estimated downtime is the period of time for a breakdown to last once it occurs. A regular activity interruption is a time period in which normal work on an activity is halted, and is defined by its start and end times. Examples include a lunch break, or a tea break. Algorithms for concurrent activity delay analysis within SDESA are not presented in this paper due to size limit. Instead, the following examples emphasize SDESA's applications and illustrate the validity and simplicity of SDESA modeling with a simple earthmoving operation simulation and a real hoist and barrow concreting operation simulation.

\section{SIMPLE EARTH-MOVING EXAMPLE}

The earthmoving process can be described as a cycle in which trucks are loaded by a shovel loader, then full trucks travel to the dump site and queue for dumping under the instruction of a flagman, and return to the loading area to queue for reloading. (Figure 1)

The information required for model setup is summarized in Tables 1, 2 and 3. Table 1 lists the time data for the working hours on site and the lunch break time. Resource requirements, resources available and their initial locations, and the duration of activities are given in Table 2. The breakdown probability and downtime for different resource types are given in Table 3. 


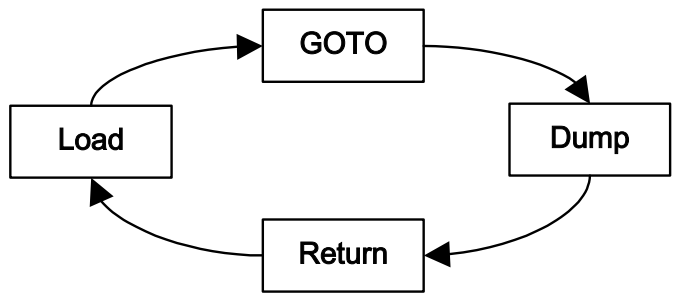

Figure 1: Earthmoving Operation Activity Sequence

Table 1: Working Hours of the Earth Moving Project

\begin{tabular}{|c|c|c|c|c|c|}
\hline $\begin{array}{c}\text { Time } \\
\text { Event }\end{array}$ & From & To & $\begin{array}{c}\text { Sim- } \\
\text { Start }\end{array}$ & $\begin{array}{c}\text { Sim- } \\
\text { End }\end{array}$ & Duration \\
\hline $\begin{array}{c}\text { Working } \\
\text { Hour }\end{array}$ & $08: 00$ & $18: 00$ & 0 & 600 & $600 \mathrm{~min}$ \\
\hline $\begin{array}{c}\text { Lunch } \\
\text { Break }\end{array}$ & $12: 00$ & $13: 00$ & 240 & 300 & $60 \mathrm{~min}$ \\
\hline
\end{tabular}

Table 2: Resource and Activity Summary

\begin{tabular}{|c|c|c|c|}
\hline Activity & $\begin{array}{c}\text { Resource } \\
\text { Required }\end{array}$ & $\begin{array}{c}\text { Resource } \\
\text { Available }\end{array}$ & Duration \\
\hline Load & $\begin{array}{c}\text { Loader X 1, } \\
\text { Truck X 1 }\end{array}$ & $\begin{array}{c}\text { Loader X 1, } \\
\text { Truck X 4 }\end{array}$ & $\begin{array}{c}\text { Constant } \\
(5)\end{array}$ \\
\hline GOTO & Truck X 1 & - & $\begin{array}{c}\text { Constant } \\
(15)\end{array}$ \\
\hline Dump & $\begin{array}{c}\text { Flagman X 1, } \\
\text { Truck X 1 }\end{array}$ & Flagman X 1 & $\begin{array}{c}\text { Constant } \\
(1)\end{array}$ \\
\hline Return & Truck X 1 & - & $\begin{array}{c}\text { Constant } \\
(12)\end{array}$ \\
\hline
\end{tabular}

Table 3: Resource Breakdown Rate and Duration

\begin{tabular}{|c|c|c|c|}
\hline $\begin{array}{c}\text { Possible } \\
\text { Breakdown } \\
\text { Resources }\end{array}$ & $\begin{array}{c}\text { Avail- } \\
\text { able } \\
\text { Units }\end{array}$ & $\begin{array}{c}\text { Breakdown } \\
\text { Probability }\end{array}$ & $\begin{array}{c}\text { Breakdown } \\
\text { Duration }\end{array}$ \\
\hline Truck & 4 & 0.1 & $3 \mathrm{~min}$ \\
\hline Loader & 1 & 0.2 & $5 \mathrm{~min}$ \\
\hline Flagman & 1 & 0 & N/A \\
\hline
\end{tabular}

Three scenarios were considered and experimented with. The base scenario ignored resource breakdowns and regular interruptions. The second scenario considered only the resource breakdowns pertaining to the loader and trucks. The third scenario considers both the one-hour regular interruption at lunch and the breakdowns for both loader and trucks.

The SDESA model (Figure 2) consists of four activities while the resources required are displayed on the left top corner of those rectangular model elements (i.e. Activities). The diamond shape element is used to initialize and control flow entities (i.e. 75 dump units to be moved). Resource breakdowns and regular interruptions are simply specified by entering respective dialog boxes (Figure 3 ). Note embedding resource breakdowns and regular interruptions into a SDESA model requires no change to be made on the model structure (Figure 2).

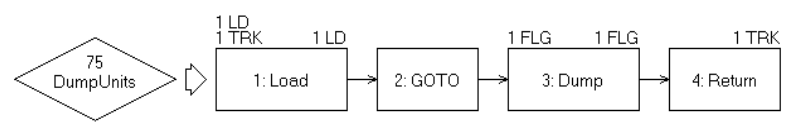

Figure 2: SDESA Model with or without Resource Breakdown and Interruption

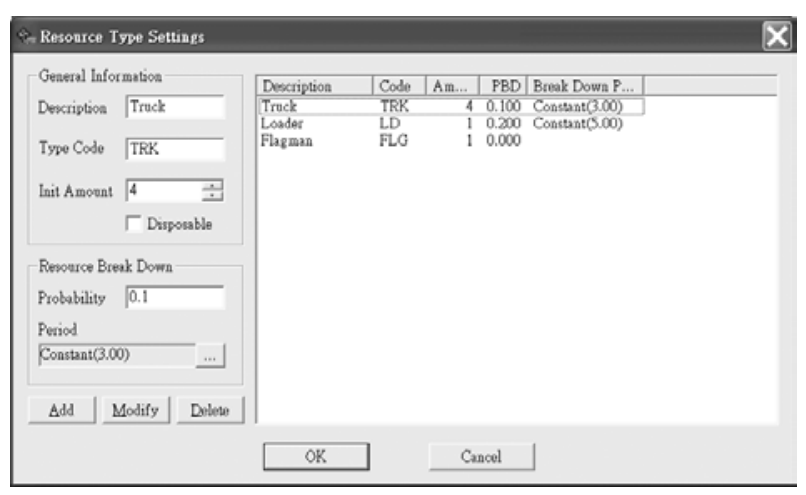

Figure 3a: Resource Type Input Box for the Definition of Random Resource Breakdowns

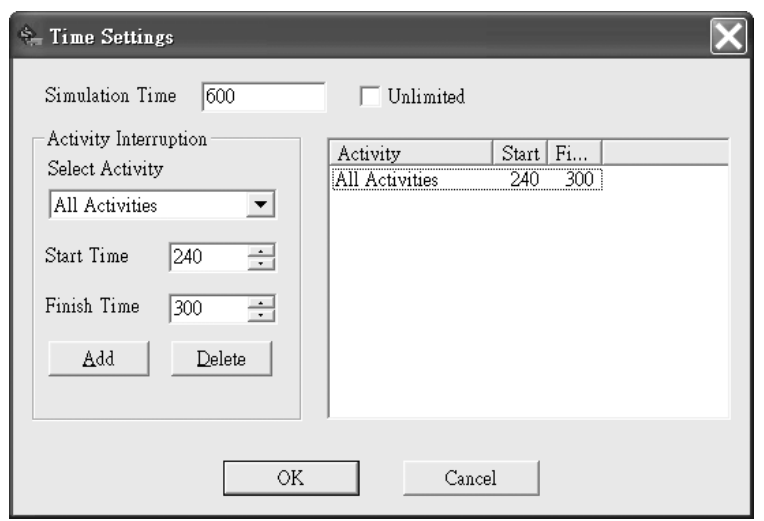

Figure 3b: Simulation Time Control for the Input of Regular Activity Interruptions

The SIMPHONY simulation platform, - a research product from the University of Alberta- provides a CYCLONE template with enhanced functionality (such as hierarchical modeling structure and probability successor branches) (AbouRizk 2000) and was utilized in the present study as a cross-validation tool. The CYCLONE model for the base scenario is composed of four activity nodes (two Combi and two Normal) and four queuing nodes (Figure 4). The consideration of resource breakdowns and the lunch break complicates the CYCLONE model (Figure 5), with six Probabilistic Arcs inserted for withdrawing the loader or the flagman during the interruption period. And the Consolidation function node is placed after the activity "Dump" to evoke the lunch break once a predefined number of dumps are completed. The activity "Lunch" has the highest priority such that the loader and the flagman can stop the earthmoving cycle and engage in the "Lunch" till the end of the lunch break. Note that a Queue node, named Control 1, contains 
one element initially, as essential to ensure the "Lunch" break occurs once only in a working day.

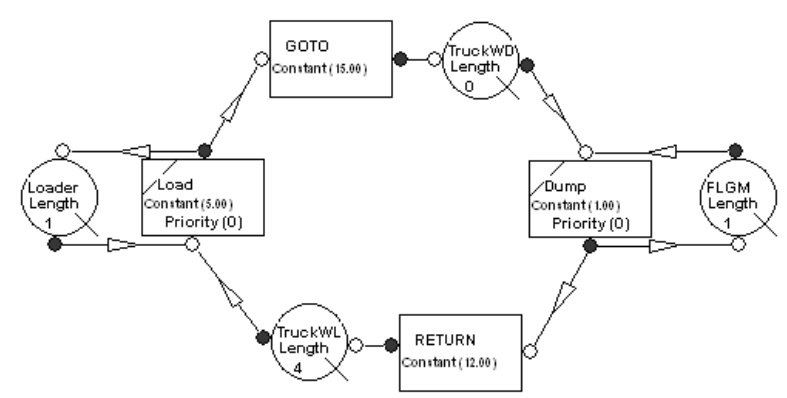

Figure 4: CYCLONE Model without Consider

Resource Breakdown and Interruption

Table 4 compares the simulation results for SDESA and CYCLONE in terms of the start-loading times on first twelve trucks as for scenarios 1, 2 and 3. Scenario 1 is deterministic (no random event involved such as probabilistic breakdowns), and the two models, as expected, give identical start-loading times. Scenario 2 and 3 are stochastic due to random resource breakdowns. Note that in scenario $2 \&$ 3 decimal numbers resulted from the SDESA model for start-loading times, as in contrast with the integers from the CYCLONE model. This is because the interruption model embedded in SDESA allows for overlapping multiple resource breakdowns during simulation. For instance, both the loader and the truck breakdown in loading a truck for 5 min and 3 min respectively, with the loader's breakdown occurring 3.5 minutes after the start of truck breakdown. As such, a decimal, yet shorter, overall delay to the loading activity is determined by overlapping two breakdowns (i.e. $6.5 \mathrm{~min}$ instead of $8 \mathrm{~min}$ ). Another noteworthy point is the slightly different start times for the lunch break in scenario 3 for the two models. In CYCLONE, as the start of lunch break depends on the 25 dump units completed at activity "Dump", the interruption occurred at 242 -2 minutes after the expected time (240) - at which moment the $25^{\text {th }}$ dump unit is completed. While SDESA interrupted the dump ac- tivity at 240 for lunch break and resumed the remainder of current activity when the lunch break ended.

\section{HOIST AND BARROW CONCRETING OPERATION}

To further assess the SDESA's modeling validity for handling interruptions in a practical setting, a real hoist and barrow concreting operation was translated into simulation models. Data about the operation was collected on a Hong Kong building site between 09:00 to 13:00 on $10^{\text {th }}$ Dec 2002 by (1) on-site observation using a digital stop watch, (2) referencing the concrete truckmixer delivery slips, and (3) interviewing the site foremen and engineers. The activity times are represented with uniform and beta distributions fitted on the site data.

The "Hoist and Barrow" concreting method used a hoist for vertical transportation of concrete in a skip. To begin with the concreting operation, a truck-mixer full of concrete arrived at the site and parked close to the feeding tip of the skip. Then, the truck-mixer unloaded concrete into the skip to its full. Upon receiving a "request concrete" signal form the upper floor, the skip controller switched on the hoist at the ground level. When the skip reached the upper floor, it stopped at the opening of a hopper, tipping concrete into the hopper. The skip then returned down the hoist to the ground level. Upon receiving another "request concrete" signal, the truck unloading and skip hoisting processes repeated. Once the hopper at the upper floor was filled, the laborers maneuvered wheelbarrows (barrowman) along temporary timber paths to collect and pour concrete into the formwork of a slab. The barrowman's work cycle was readily identified, i.e. collecting concrete into wheelbarrows, traveling to the pour destination, placing concrete, traveling back to the hopper, and collecting concrete from the hopper again. Once the hopper was empty, the barrowmen just pressed a bell button to alarm the controller at ground level and request another skip-load of concrete. Once the truckmixer was emptied, it left the unloading bay and moved

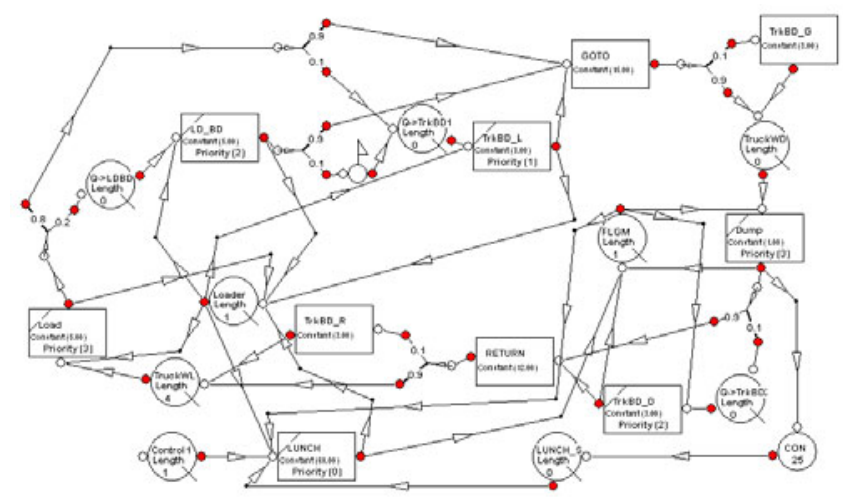

Figure 5: CYCLONE Model Considering Resource Breakdown and Interruption 
Table 4: Start Time of Loading and Lunch in Different Scenarios

\begin{tabular}{|c|c|c|c|c|c|c|}
\hline $\begin{array}{c}\text { Load } \\
\text { Time }\end{array}$ & \multicolumn{2}{|l|}{ Scenario 1: Base Scenario } & \multicolumn{2}{l|}{ Scenario 2: Resource Breakdown } & $\begin{array}{c}\text { Scenario 3: Resource Breakdown } \\
\text { plus Activity Interruption }\end{array}$ \\
\hline$\#$ & CYCLONE & SDESA & CYCLONE & SDESA & $\begin{array}{c}\text { CYCLONE } \\
\text { SDESA }\end{array}$ \\
\hline 1 & 0 & 0 & 0 & 0 & 0 & 0 \\
\hline 2 & 5 & 5 & 8 & 11.23 & 18 & 11.23 \\
\hline 3 & 10 & 10 & 18 & 16.23 & 28 & 21.23 \\
\hline 4 & 15 & 15 & 28 & 21.23 & 36 & 42.23 \\
\hline 5 & 33 & 33 & 36 & 42.23 & 46 & 52.23 \\
\hline 6 & 38 & 38 & 46 & 52.23 & 59 & 57.23 \\
\hline 7 & 43 & 43 & 59 & 57.23 & 64 & 62.23 \\
\hline 8 & 48 & 48 & 64 & 62.23 & 84 & 80.23 \\
\hline 9 & 66 & 66 & 69 & 80.23 & 92 & 90.23 \\
\hline 10 & 71 & 71 & 84 & 85.23 & 102 & 98.23 \\
\hline 11 & 76 & 76 & 92 & 90.23 & 242 & 240 \\
\hline 12 & 81 & 81 & 102 & 98.23 & - & \\
\hline Lunch & -- & -- & -- & -23 & & \\
\hline
\end{tabular}

to the washing bay, where the truck was cleaned before departing from the site.

Table 5 summarizes the time distribution and resource requirement for activities in the concreting operation. And Table 6 lists the observed resource breakdown and activity interruptions. To simplify the modeling, occasional repositioning and stabilizing the temporary timber paths by barrowmen is treated as random breakdowns on barrowmen resources while the lunch break and tea break as regular activity interruptions on the job site.

Note the actual resources available on the site were 1 record laborer, 1 skip controller, 2 hopper ports, and 4 barrowman; 14 truck loads of concrete were delivered, each carrying $7 \mathrm{~m}^{3}$, the volume capacities for the skip, the hopper, and the wheelbarrow were $0.7 \mathrm{~m}^{3}, 0.9 \mathrm{~m}^{3}$, $0.055 \mathrm{~m}^{3}$, respectively.

\subsection{The CYCLONE Model}

The CYCLONE model was set up in the SIMPHONY template (Figure 6), consisting of three major loops representing the working cycles for the truck-mixer, the skip, and the barrowman. The loops were then interconnected with QUEUE and COMBI activities to denote the interchange of resource/information units between loops. As a result, the linking arrows may cross one another (such as Skip Controller Que node), rendering the model illegible. A COUNTER node was placed after the "Truck Leave

Table 5: Data Summary of Activity and Resources Requirement of the Concreting Project

\begin{tabular}{|c|c|c|}
\hline Activity & Time Distribution & Required Resources \\
\hline Truck park into the site and setup & $1.5-3.5$ (Uniform) & $\begin{array}{c}\text { 1Truck, 1Record Laborer, } \\
\text { 1Unloading Bay }\end{array}$ \\
\hline Unload concrete to skip & $0.3,0.9,0.6,1.9(\mathrm{~L}, \mathrm{U}, \mathrm{a}, \mathrm{b})$ & 1Skip Controller \\
\hline Hoist up skip & 0.25 (Constant) & $\begin{array}{c}\text { 1Skip Controller, 1Request } \\
\text { Signal from U/F }\end{array}$ \\
\hline Pour concrete to hopper & 0.14 (Constant) & 1Skip Controller \\
\hline Skip return to G/F & $0.25($ Constant) & 1Skip Controller \\
\hline Barrowman collect concrete & $0.1,0.4,1,3.2(\mathrm{~L}, \mathrm{U}, \mathrm{a}, \mathrm{b})$ & $\begin{array}{c}\text { 1Hopper Collection Port, } 1 \\
\text { Barrowman }\end{array}$ \\
\hline Barrowman travel to dump & $0.2,0.4,10.2,10.3(\mathrm{~L}, \mathrm{U}, \mathrm{a}, \mathrm{b})$ & 1 Barrowman \\
\hline Barrowman dump concrete & $0.03,0.18,4.2,5.2(\mathrm{~L}, \mathrm{U}, \mathrm{a}, \mathrm{b})$ & 1 Barrowman \\
\hline Barrowman return to collect & $0.2,0.4,1.4,1.7(\mathrm{~L}, \mathrm{U}, \mathrm{a}, \mathrm{b})$ & 1 Barrowman \\
\hline Truck washing & $2-2.8($ Uniform) & 1Truck, 1Skip Controller \\
\hline Truck Leave Site & $0.5-1.25($ Uniform) & 1Truck, 1Record Laborer \\
\hline
\end{tabular}


Site" COMBI activity in order to collect statistics on truckmixer unloading cycle times.

Table 6: Observed Resource Breakdown and Activity Interruptions during the Concreting Operation

\begin{tabular}{|c|c|c|}
\hline Observation & Parameter & Description \\
\hline $\begin{array}{c}\text { Probability- } \\
\text { based resource } \\
\text { breakdown }\end{array}$ & $\begin{array}{c}\text { Resource: Wheel } \\
\text { Barrow man } \\
\text { Probability: } 0.05 \\
\text { Duration: } 0.2-0.8 \\
\text { mins (uniform) }\end{array}$ & $\begin{array}{c}\text { Wheel barrow } \\
\text { man reposition } \\
\text { the timber path } \\
\text { from time to time }\end{array}$ \\
\hline & $\begin{array}{c}\text { Lunch Break: } \\
\text { Regular inter- } \\
\text { ruption }\end{array}$ & $\begin{array}{c}\text { All works are } \\
\text { Tea Break: }\end{array}$ \\
& $450-465(3: 30-$ & $\begin{array}{c}\text { stopped during } \\
\text { lunch and tea } \\
\text { breaks. }\end{array}$ \\
& $3: 45)$ & \\
\hline
\end{tabular}

\subsection{The SDESA Model}

The counterpart SDESA model (Figure 7) shows the three major working cycles for the truck-mixer, the skip, and the wheel barrow. The activities were linked up in a sequence similar to the CPM method, and the required resources were assigned to activities. Interdependencies between different cycles were modeled using disposable resources, which were generated by one activity and required by another. For example, 10 skip loads of concrete were generated at the end of "Park and Setup" a truckmixer; these disposable resources were required to initialize the activity "Unload Conc To Skip" along the skip cycle. The flow entities were 14 truckmixers, 1 skip, and 4 wheelbarrows for the three cycles respectively.

Furthermore, a "SDESA+" model was also created based on the above SDESA model to take into account the observed job site disruptions listed in Table 6, i.e. the probability-based barrowmen's breakdowns for repositioning the temporary timber paths, and the lunch/tea breaks. The model structure for "SDESA+" remains unchanged as Figure 7. Note that the counterpart CYCLONE model accommodating those interruptions would be too convoluted and hence was not attempted. In order to test the predicting performance of the CYCLONE and SDESA models, they were executed on a PC for 20 runs and the averaged results were compared as shown in Tables 7 and 8 . Table 7 lists the just-in-time arrival times for the first five truckmixers predicted by three models [columns (a), (b), and (c)], as compared with the actually observed arrival times, on which moments, the trucks should arrive on site to keep a continuous concrete supply without queuing on site. Table 8 shows the pour duration (i.e. the last truckmixer departure time) predicted by three models, as compared with the actual case. Note that a total of 75 minutes [the lunch break (60 minutes) plus the tea break (15 minutes)] was accrued to the last truckmixer's departure time to determine the pour duration for the CYCLONE and SDESA models which did not explicitly account for those interruptions. The two models produced considerably large errors. By contrast, the "SDESA+" model which took into consideration all the interruptions was deem valid by giving more accurate simulation results that closely matched the actual situations.

\section{CONCLUSION}

This paper has focused on how to model the resource breakdowns and regular interruptions in construction operations simulation, and introduced the newly developed enhanced version of the Simplified Discrete Event Simulation Approach (SDESA) that makes construction simulations more realistic and, at the same time, retains the simplicity of modeling. The well-established CYCLONE method was used to check the result given by SDESA on a simple earthmoving operation simulation, and a Hoist and Barrow concreting operation simulation. The simulation results show that the explicit and proper consideration of operational interruptions in construction simulations is vital to obtaining valid models and hence accurate predictive information from simulations.

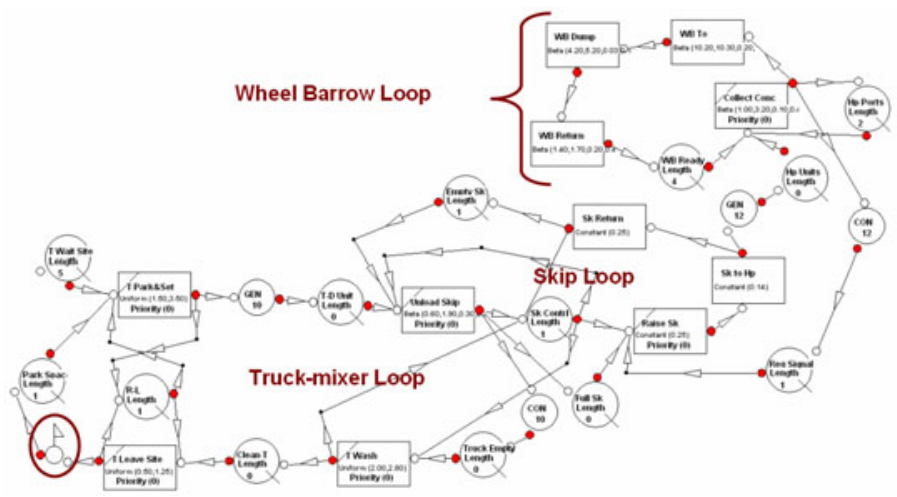

Figure 6: CYCLONE Model for the Hoist and Barrow Concreting Operation 


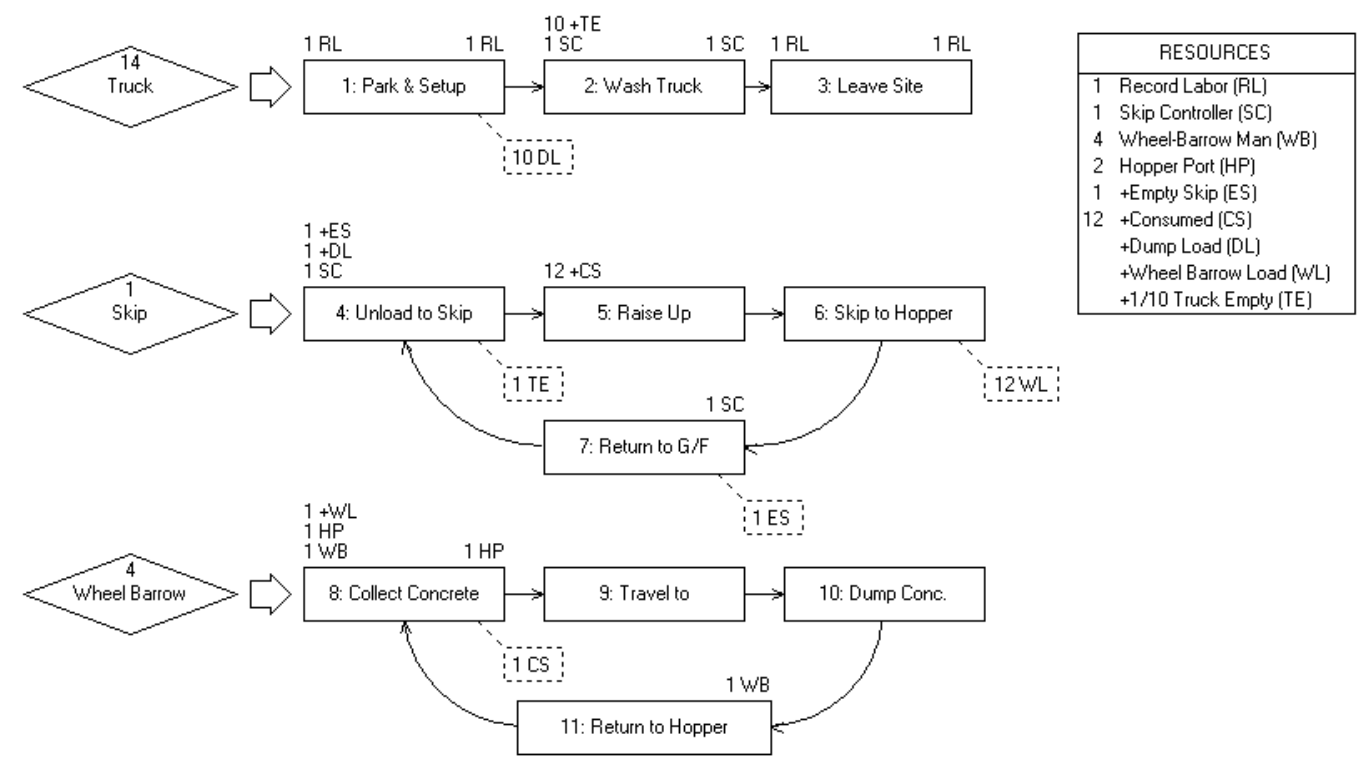

Figure 7: SDESA Model for the Hoist and Barrow Concreting Operation

Table 7: Prediction of the Optimum Truckmixer Arrival Time by Taking the Average of 20 Runs

\begin{tabular}{|c|c|c|c|c|}
\hline Truck & $\begin{array}{c}\text { CYCLONE } \\
\text { (a) }\end{array}$ & $\begin{array}{c}\text { SDESA } \\
\text { (b) }\end{array}$ & $\begin{array}{c}\text { SDESA+ } \\
\text { (c) }\end{array}$ & $\begin{array}{c}\text { Observed } \\
\text { (d) }\end{array}$ \\
\hline 1 & 0 & 0 & 0 & 0 \\
\hline 2 & 28.5 & 28.3 & 36 & 40 \\
\hline 3 & 57.1 & 56.5 & 63 & 73 \\
\hline 4 & 85.6 & 84.9 & 93 & 111 \\
\hline 5 & 114.0 & 113.1 & 123 & 138 \\
\hline
\end{tabular}

Table 8: Predicting the Leave Time of the Last $\left(14^{\text {th }}\right)$ Truck-Mixer by Taking the Average of 20 Runs

\begin{tabular}{|c|c|c|c|c|}
\hline & $\begin{array}{c}\text { CYCLONE } \\
\text { (a) }\end{array}$ & $\begin{array}{c}\text { SDESA } \\
(\mathrm{b})\end{array}$ & $\begin{array}{c}\text { SDESA+ } \\
\text { (c) }\end{array}$ & $\begin{array}{c}\text { Actual } \\
(\mathrm{d})\end{array}$ \\
\hline $\begin{array}{c}\text { Last Truck Leave } \\
\text { Site }\end{array}$ & $\begin{array}{c}397.7+75 \\
=472.7\end{array}$ & $\begin{array}{c}398.9+75 \\
=473.9\end{array}$ & 572.9 & 570 \\
\hline
\end{tabular}

\section{ACKNOWLEDGMENTS}

The research was financially supported by the Research Grant Council of the Hong Kong Government under a grant A/C No. BQ-580, PolyU 5049 \02E.

\section{REFERENCES}

AbouRizk, S., (2000), SIMPHONY User Guide, Construction Engineering and Management, the University of Alberta, Canada.

Bernold, Leonhard E. (1989), "Simulation of nonstaedy construction processes", Journal of Construction Engineering and Management, ASCE., Vol. 115, No.2, pp. $163-178$
Damrianant, J. and Wakefield, R. R. (2000), “An alternative approach for modeling of interference in discreteevent systems", Civil. Eng. and Env. Syst., Vol. 17, pp. 213-235

Halpin, D. W. (1977), "CYCLONE - method for modeling job site processes.", Journal of Construction Division, ASCE., Vol. 103, No.3, pp.489-499

Halpin, D. W. and Riggs, L. (1992), Planning and analysis of construction operations, Wiley, New York.

Law, A. M. and Kelton, W. D. (1982), Simulation modeling and analysis, $3^{\text {rd }}$ Edition, McGraw-Hill, Boston.

Lu, M. (2003a) "Simplified Discrete-Event Simulation Approach for Construction Simulation", Journal of Construction Engineering and Management, ASCE, Vol. 129, No.5, pp 537-546 
Lu, M. (2003b), SDESA's User Guide, Hong Kong Polytechnic University.

Martinez, J. C. and Ioannou, P. G. (1999) "GeneralPurpose Systems for Effective Construction Simulation", Journal of Construction Engineering and Management, ASCE, Vol. 125, No.4, pp 265-276

McCahill, D. F. and Bernold, Leonhard E. (1993), "Resource-oriented modeling and simulation in construction", Journal of Construction Engineering and Management, ASCE., Vol. 119, No. 3, pp. 590-606

Parker, H. W. and Oglesby, C. H. (1972), Method improvement for construction managers, McGraw-Hill Book Company, New York.

Paulson, B. C. (1995), "Computer and Construction - Midcareer Reflections", Journal of Construction Engineering and Management, ASCE., Vol. 121, No. 2, pp. 197-200

Shi, J. and AbouRizk, S. (1997), "Resource Based Modeling for Construction Simulation", Journal of Construction Engineering and Management, ASCE., Vol. 123, No. 1, pp. 26-33

\section{AUTHOR BIOGRAPHIES}

MING LU is Assistant Professor of Construction Engineering \& Management with the Department of Civil and Structural Engineering of the Hong Kong Polytechnic University. He received a Ph.D. degree from the University of Alberta, Canada. His research interest is around computational construction project management aided by artificial intelligence and computer simulations. In recent years, Dr. LU has developed the novel approaches for neural networks modeling, resource scheduling and operations simulation for enhancing efficiency and productivity of complex construction systems; those developments have been published in the prestigious ASCE journals on construction engineering and management, and computing methods. Dr. $\mathrm{Lu}$ is a member of ASCE, and the recipient of a National Science and Engineering Research Council of Canada Industrial Award (1999) and the Robert Stollery USF and G Insurance Company of Canada Award in Construction Engineering and Management (2000). His email address is <cemlu@inet.polyu.edu.hk>

WAH-HO CHAN received a civil and structural engineering bachelor degree from the Hong Kong Polytechnic University in 2002, and is now Research Assistant of the Department of Civil and Structural Engineering of the Hong Kong Polytechnic University. His research interest is around construction engineering and management, in particular, looking into current construction practices and making improvement on them through computer-modeling and IT application. He participated in an optimized resource scheduling project and is actively involved in an ongoing research project on construction operations/logistics simulation. 